\title{
CBS-BERICHTEN
}

\section{Duurzame inzetbaarheid van zelfstandig ondernemers zonder personeel}

\author{
Wouter van der Torre \& Henk-Jan Dirven*
}

Zelfstandig ondernemers zonder personeel zijn positiever over hun eigen duurzame inzetbaarheid dan werknemers. Ze vinden vaker dat ze goed functioneren en willen later met pensioen. Daarnaast ervaren ze minder werkdruk, hebben ze minder vaak burn-outklachten, zijn ze meer bevlogen en vinden ze hun werk gevarieerder. Wel doen zelfstandig ondernemers vaker zwaar werk en voelen ze zich vaker fysiek zwaar belast. Dat geldt met name voor zelfstandig ondernemers zonder personeel in de nijverheid en energie, waartoe de bouw en industrie worden gerekend. Dit artikel is gebaseerd op een secundaire analyse van de Nationale Enquête Arbeidsomstandigheden (NEA) en de nieuwe Zelfstandigen Enquête Arbeid (ZEA).

\section{Inleiding}

Zelfstandig ondernemers zonder personeel zijn personen die voor eigen rekening of risico arbeid verrichten in een eigen bedrijf of praktijk en geen personeel in dienst hebben. Hun aantal is de laatste jaren flink gegroeid. Waren er in 2003 nog een kleine 570.000 personen met een hoofdbaan als zelfstandig ondernemer zonder personeel, in 2015 was dat opgelopen tot ruim 900.000 (bron: CBS, Enquête Beroepsbevolking). Dit roept de vraag op wat de positieve en negatieve gevolgen van deze ontwikkeling zijn voor de samenleving als geheel en de individuen die het betreft.

Een eerste stap bij het beantwoorden van deze vraag is het beschrijven van de arbeidssituatie van zelfstandig ondernemers. Het interdepartementaal beleidsonderzoek naar zzp'ers (Ministerie van Financiën, 2015) heeft daaraan een belangrijke bijdrage geleverd. Aanvullend daarop hebben TNO en CBS (Van der Torre et al., 2016) onderzoek gedaan naar de duurzame inzetbaarheid van zelfstandig ondernemers. Het belang van duurzame inzetbaarheid neemt toe nu van werkenden wordt verwacht dat zij later met pensioen gaan. Bovendien vereisen diensteninnovatie en ook technologische en sociale vernieuwing dat werkenden zich voortdurend blijven ontwikkelen om hun inzetbaarheid op peil te houden.

De centrale vraag in deze bijdrage luidt als volgt: In hoeverre verschilt de duurzame inzetbaarheid van zelfstandig ondernemers zonder personeel van die van werknemers

* Wouter van der Torre is werkzaam bij TNO. E-mail: wouter.vandertorre@tno.nl. HenkJan Dirven is werkzaam bij CBS. 
(d.w.z. werkenden in loondienst)? Deze analyse is zowel univariaat als multivariaat uitgevoerd, waarbij gecorrigeerd is voor leeftijd, onderwijsniveau, geslacht en bedrijfstak. Alvorens de centrale vraag te beantwoorden wordt een korte beschrijving gegeven van de demografische en sociaaleconomische verschillen tussen beide groepen.

\section{Methode en definities}

Zelfstandig ondernemers zonder personeel vormen met ruim 900.000 de hoofdmoot van de bijna 1,4 miljoen personen die in 2015 een hoofdbaan als zelfstandige hadden. De andere zelfstandigen zijn zelfstandigen met personeel, meewerkende gezinsleden en overige zelfstandigen, zoals personen die belastingaangifte doen over 'inkomen uit overige arbeid'. In deze laatste groep - die dus niet is meegenomen in de analyse - bevinden zich onder andere postbestellers en alfahulpen.

Duurzame inzetbaarheid is gedefinieerd als het vermogen om gezond, vitaal en productief deel te nemen aan (betaalde) arbeid tot de pensioengerechtigde leeftijd (Kraan et al., 2014). Om duurzame inzetbaarheid in kaart te brengen zijn items op het gebied van duurzame inzetbaarheid geselecteerd uit de Nationale Enquête Arbeidsomstandigheden (NEA) en Zelfstandigen Enquête Arbeid (ZEA). Dit zijn bijvoorbeeld ziekteverzuim, functioneren, willen en kunnen doorwerken tot op hoge leeftijd, zwaar en moeilijk werk, fysieke en mentale belasting, tevredenheid, autonomie en de behoefte aan opleiding. Deze variabelen zijn indicatoren voor de inzetbaarheid op korte en/of langere termijn. De leeftijd tot waarop een respondent denkt te kunnen blijven werken, is bijvoorbeeld een indicator voor de langere termijn inzetbaarheid. Fysieke belasting is in eerste instantie een kortetermijnindicator, maar een grote mate van belasting op korte termijn kan ook gevolgen hebben op de langere termijn. De selectie van indicatoren is gebaseerd op eerder onderzoek (Brouwer et al., 2012; Kraan et al., 2014), maar was beperkt tot kenmerken die in de NEA en de ZEA op vergelijkbare manier bevraagd zijn (zie tabel 1).

\section{Tabel 1 Geselecteerde indicatoren duurzame inzetbaarheid}

Indicator Omschrijving

- Centrale inzetbaarheids- Verzuimpercentage, goed functioneren, door willen werken tot maten

- Gezondheid ... jaar, door kunnen werken tot ... jaar

- Werkgerelateerd Ervaren gezondheid, burn-outklachten

- Werk-privébalans Wennis en vaardigheden

- Inhoud Taakeisen, autonomie, gevarieerd werk, zwaar werk, moeilijkheidsgraad/cognitieve belasting

- Omstandigheden Fysieke belasting, mentale belasting, tevredenheid arbeidsomstandigheden 
Dit bericht is gebaseerd op een secundaire analyse van gegevens uit de NEA 2014 en de ZEA 2015. Beide onderzoeken zijn uitgevoerd door TNO en CBS in samenwerking met het ministerie van Sociale Zaken en Werkgelegenheid. De data voor de NEA zijn eind 2014 verzameld en de data voor de ZEA begin 2015 . De gewogen bruto respons van de NEA 2014 bedroeg 30,8\% en van de ZEA $29,4 \%{ }^{1}$ In aanvulling op deze bronnen zijn gegevens uit de Enquête Beroepsbevolking (EBB) van het CBS gebruikt om de demografische en sociaaleconomische kenmerken van zelfstandig ondernemers en werknemers te beschrijven.

De vergelijking van de duurzame inzetbaarheid van zelfstandig ondernemers zonder personeel en werknemers is niet alleen bivariaat uitgevoerd. Er is ook multivariaat geanalyseerd, waarbij gecorrigeerd is voor leeftijd, onderwijsniveau, geslacht en bedrijfstak. Dat is gebeurd om na te gaan of de verschillen tussen beide groepen worden veroorzaakt door een andere samenstelling naar deze kenmerken. Tevens zijn de gegevens uitgesplitst naar leeftijdsgroepen, onderwijsniveaus en bedrijfstakken. Zo zijn bijvoorbeeld binnen de bedrijfstak nijverheid en energie de zelfstandig ondernemers zonder personeel en werknemers met elkaar vergeleken. In dit bericht worden de resultaten van deze uitsplitsingen alleen beschreven als er opvallende uitkomsten waren.

\section{Demografische en sociaaleconomische verschillen}

Zelfstandig ondernemers zonder personeel en werknemers verschillen van elkaar in demografisch en sociaaleconomisch opzicht (zie ook Kösters, 2016). Zo zijn de ondernemers een stuk ouder dan de werknemers. Bij zelfstandig ondernemers zonder personeel gaat het ook vaker dan bij werknemers om mannen. Verder zijn zelfstandig ondernemers zonder personeel relatief hoogopgeleid.

Zelfstandig ondernemers zonder personeel maken meer uren dan werknemers. De zelfstandig ondernemers zijn vaker dan werknemers werkzaam in de landbouw, de bouwnijverheid, de zakelijke dienstverlening en de cultuur, sport en recreatie. Zij hebben verhoudingsgewijs vaak een beroep als auteur of kunstenaar, als bouwarbeider en als tuinder, akkerbouwer of veeteler. Werknemers werken relatief vaak in de gezondheidszorg, de industrie en het openbaar bestuur. Zij werken vaker dan zelfstandig ondernemers zonder personeel als administratief personeel, als schoonmakers en keukenhulpen en als verzorgenden.

Bij een voltijdse werkweek is het persoonlijk jaarinkomen van zelfstandig ondernemers zonder personeel lager dan dat van werknemers. In 2014 bedroeg het gemiddeld bijna 37.000 euro. Voltijdse werknemers hadden een inkomen van gemiddeld bijna 50.000 euro per jaar. De koopkracht van beide groepen blijkt echter maar weinig uiteen te lopen. Het aan zelfstandig ondernemers zonder personeel toegekende gestandaardiseerde inkomen van het bijbehorende huishouden was namelijk vrijwel gelijk aan dat van werknemers. Als rekening wordt gehouden met huishoudenssamenstelling, inkomens van andere huishoudensleden, inkomensoverdrachten en met belastingen en premies, dan blijkt het lagere persoonlijke inkomen van zelfstandig ondernemers zonder personeel dus niet gepaard te gaan met een geringere koopkracht. 
Tabel 2 Demografische en sociaaleconomische kenmerken van zelfstandig ondernemers zonder personeel en werknemers (15-74 jaar), 2014

\begin{tabular}{|c|c|c|}
\hline Kenmerken & $\begin{array}{l}\text { Zelfstandig ondernemers } \\
\text { zonder personeel }\end{array}$ & Werknemers \\
\hline Gemiddelde leeftijd & 47 jaar & 40 jaar \\
\hline Geslacht: percentage mannen & $65 \%$ & $52 \%$ \\
\hline $\begin{array}{l}\text { Onderwijsniveau: percentage hoogop- } \\
\text { geleiden }\end{array}$ & $42 \%$ & $34 \%$ \\
\hline Gemiddelde arbeidsduur per week & 36 uur & 30 uur \\
\hline $\begin{array}{l}\text { Bedrijfstakken waarin relatief vaak } \\
\text { werkzaam }\end{array}$ & $\begin{array}{l}\text { - landbouw } \\
\text { - bouwnijverheid } \\
\text { - zakelijke dienstverlening } \\
\text { - cultuur, sport en recre- } \\
\text { atie }\end{array}$ & $\begin{array}{l}\text { - gezondheidszorg } \\
\text { - } \text { industrie } \\
\text { - openbaar bestuur }\end{array}$ \\
\hline $\begin{array}{l}\text { Beroepssegmenten waarin relatief vaak } \\
\text { werkzaam }\end{array}$ & $\begin{array}{l}\text { - } \text { auteurs en kunstenaars } \\
\text { - bouwarbeiders } \\
\text { - tuinders, akkerbouwers } \\
\text { en veetelers } \\
\text { - vakspecialisten op artis- } \\
\text { tiek en cultureel gebied }\end{array}$ & $\begin{array}{l}\text { - } \text { administratief personeel } \\
\text { - } \text { schoonmakers en } \\
\text { keukenhulpen } \\
\text { - verzorgenden } \\
\text { - hulpkrachten transport } \\
\text { en logistiek }\end{array}$ \\
\hline $\begin{array}{l}\text { Gemiddeld persoonlijk jaarinkomen } \\
\text { bij voltijdse werkweek* }\end{array}$ & 36.900 euro & 49.900 euro \\
\hline $\begin{array}{l}\text { Gemiddeld gestandaardiseerd huishou- } \\
\text { densinkomen (koopkracht)* }\end{array}$ & 28.200 euro & 28.100 euro \\
\hline
\end{tabular}

Bron: EBB; * voorlopige cijfers

\section{Verschillen in inzetbaarheid}

Als het gaat om duurzame inzetbaarheid, dan komen zelfstandig ondernemers zonder personeel op veel aspecten positief uit de vergelijking met werknemers. Tabel 3 presenteert de indicatoren voor duurzame inzetbaarheid die statistisch significante verschillen tussen beide groepen laten zien en waarvoor een effectgrootte is vastgesteld van minimaal 0,20 (op basis van Cohen's d; Cohen, 1988). Hierbij is nog geen rekening gehouden met verschillen tussen zelfstandig ondernemers en werknemers in andere kenmerken, zoals leeftijd, onderwijsniveau, geslacht en bedrijfstak.

Zelfstandig ondernemers zonder personeel blijken positiever over hun eigen functioneren dan werknemers. Het gaat daarbij om het oordeel van werknemers over de uitvoering van het werk, het behalen van doelen en de eigen prestaties. Ook willen zelfstandig ondernemers tot op hogere leeftijd doorwerken dan werknemers. Bovendien denken zij daartoe lichamelijk en geestelijk langer in staat te zijn. Overigens hangt dit wel af van de bedrijfstak. Binnen de bedrijfstak nijverheid en energie, waartoe de bouw en industrie worden gerekend, ligt de leeftijd tot wanneer zelfstandig ondernemers zonder personeel willen en kunnen doorwerken lager dan in andere bedrijfstakken en is het verschil met werknemers het kleinst. In de nijverheid en energie willen zelfstandig ondernemers zonder personeel tot hun 64ste blijven werken en werknemers tot hun 63ste. De leeftijd tot waarop beide groepen denken te kunnen blijven werken is gelijk, namelijk 63 jaar. 
Tabel 3 Verschillen duurzame inzetbaarheid zelfstandig ondernemers zonder personeel en werknemers

\begin{tabular}{|c|c|c|}
\hline Variabelen & $\begin{array}{c}\text { Zelfstandig } \\
\text { ondernemers } \\
\text { zonder personeel }\end{array}$ & Werknemers \\
\hline $\begin{array}{l}\text { Goed functioneren } \\
\text { Gemiddelde van schaal: I = helemaal niet mee } \\
\text { eens }-5=\text { helemaal mee eens; } 3 \text { items }\end{array}$ & $4,35 \wedge$ & 4,16 \\
\hline $\begin{array}{l}\text { Tot welke leeftijd wilt u doorgaan met werken? } \\
\text { Gemiddelde leeftijd in jaren }\end{array}$ & 674 & 63 \\
\hline $\begin{array}{l}\text { Tot welke leeftijd denkt } \mathrm{u} \text { - lichamelijk en geeste- } \\
\text { lijk - in staat te zijn om uw huidige werk voort } \\
\text { te zetten? } \\
\text { Gemiddelde leeftijd in jaren }\end{array}$ & 674 & 63 \\
\hline $\begin{array}{l}\text { Burn-outklachten } \\
\text { Antwoord 'ja' (score bóven } 3.20 \text { op schaal I t/m } \\
\text { 7) }\end{array}$ & $7 \%$ v & $14 \%$ \\
\hline $\begin{array}{l}\text { Bevlogenheid } \\
\text { Gemiddelde van schaal: } I=\text { nooit }-7=\text { elke dag; } \\
3 \text { items }\end{array}$ & $5,99 \wedge$ & 5,53 \\
\hline $\begin{array}{l}\text { Behoefte aan opleiding? } \\
\text { Antwoord: 'nee' }\end{array}$ & $66 \%$ & $53 \%$ \\
\hline $\begin{array}{l}\text { Mist } u \text { of verwaarloost } u \text { uw werkzaamheden door } \\
\text { familie- en gezinsverantwoordelijkheden? } \\
\mid=\text { nee, nooit }-4=\text { ja, zeer vaak }\end{array}$ & $\mathrm{I}, 47 \wedge$ & $|, 3|$ \\
\hline $\begin{array}{l}\text { Werkdruk/taakeisen } \\
\text { Gemiddelde van schaal: I = nooit }-4=\text { altijd; } 3 \\
\text { items }\end{array}$ & $2,20 \nabla$ & 2,37 \\
\hline $\begin{array}{l}\text { Autonomie } \\
\text { Gemiddelde van schaal: } 1=\text { nee }-3=\text { ja, regel- } \\
\text { matig; } 5 \text { items }\end{array}$ & $2,80 \wedge$ & 2,46 \\
\hline $\begin{array}{l}\text { Gevarieerd werk } \\
\text { Gemiddelde van schaal: I = nooit }-4=\text { altijd; } 3 \\
\text { items }\end{array}$ & $2,94 \wedge$ & 2,69 \\
\hline $\begin{array}{l}\text { Zwaar werk - Maakt u bij uw werk gebruik van } \\
\text { een gereedschap, apparaat of voertuig dat trillingen } \\
\text { of schudden veroorzaakt? } \\
I=\text { nee }-3=\text { ja, regelmatig }\end{array}$ & $\mathrm{I}, 44 \wedge$ & 1,26 \\
\hline $\begin{array}{l}\text { Fysieke belasting - Ik kan gemakkelijk voldoen aan } \\
\text { de fysieke eisen die mijn werk aan mij stelt } \\
I=\text { helemaal niet mee eens }-4=\text { helemaal mee } \\
\text { eens }\end{array}$ & $3,10 \mathrm{v}$ & 3,32 \\
\hline
\end{tabular}

Percentages zijn kolompercentages, getoetst met de Pearson $X^{2}$ test (horizontale vergelijkingen). Gemiddelden zijn getoetst met de t-test (horizontale vergelijkingen). Het contrast is zelfstandig ondernemers versus werknemers. $\Delta: P<0,05$ (en $\nabla$ ): significant hoger (lager) percentage en/of gemiddelde (2-zijdig getoetst) én Cohen's d effectgrootte is ten minste 0,20.

Bron: NEA en ZEA

Ook in een aantal andere opzichten laten zelfstandig ondernemers zonder personeel substantiële verschillen zien ten opzichte van werknemers op indicatoren voor inzetbaarheid op korte en langere termijn. Zo hebben zij duidelijk minder behoefte aan opleiding en cursussen. Dit sluit aan bij ander onderzoek waaruit blijkt dat zelfstandigen minder vaak opleidingen en trainingen volgen dan 
werknemers (Vlasblom et al., 2015). Aangezien zelfstandig ondernemers zonder personeel ook iets vaker aangeven dat het werk goed aansluit op hun competenties, zou dit positief kunnen worden geïnterpreteerd. Maar de geringere behoefte kan er bijvoorbeeld ook op wijzen dat zij het belang van opleidingen en cursussen onderschatten.

Daarentegen hebben zelfstandigen over het algemeen meer mogelijkheden om informeel te leren tijdens de uitvoering van hun werkzaamheden. Zo geven zelfstandig ondernemers zonder personeel vaker dan werknemers aan gevarieerd werk te hebben, waarbij het nodig is dat men nieuwe dingen leert en waarbij ook creativiteit is vereist. Ook hebben zij meer autonomie, waarbij het onder meer gaat om het zelfstandig bedenken van oplossingen voor problemen. De grotere variatie en autonomie in het werk bieden zelfstandig ondernemers verhoudingsgewijs dan ook meer ontwikkelmogelijkheden.

Zelfstandig ondernemers zonder personeel zijn meer bevlogen in hun werk dan werknemers en hebben minder vaak burn-outklachten. Zo heeft $7 \%$ van de zelfstandig ondernemers burn-outklachten ten opzichte van $14 \%$ van de werknemers. Hieraan ten grondslag ligt onder meer de geringere werkdruk die door de ondernemers zonder personeel wordt ervaren. Hun grotere autonomie biedt tevens mogelijkheden om beter met werkdruk om te gaan.

Ook de werk-privébalans is van belang voor de inzetbaarheid. Zelfstandig ondernemers zonder personeel werken meer dan werknemers 's avonds en in het weekend. Hierdoor zijn werk en privé veelal minder duidelijk gescheiden. De balans tussen beide blijkt bij de zelfstandig ondernemers dan ook iets minder goed. Zelfstandig ondernemers geven vooral vaker aan dat werkzaamheden worden gemist of verwaarloosd door familie- en gezinsverantwoordelijkheden. Overigens geven maar weinig zelfstandig ondernemers en werknemers aan dat werkzaamheden of familie- of gezinsverantwoordelijkheden worden gemist of verwaarloosd.

Tot slot vormt de fysieke arbeidsbelasting een belangrijk aspect voor de inzetbaarheid, niet alleen op de korte maar ook op de lange termijn. Zelfstandig ondernemers zonder personeel geven, in vergelijking met werknemers, minder vaak aan gemakkelijk te kunnen voldoen aan de fysieke eisen van het werk. Zij geven ook vaker aan zwaar werk te moeten verrichten. Dit speelt relatief sterk in de nijverheid en energie en in de landbouw, bosbouw en visserij. Vooral zelfstandig ondernemers zonder personeel die in de bouw werken, verrichten relatief vaak zwaar werk en kunnen naar eigen zeggen minder gemakkelijk aan de fysieke eisen van het werk voldoen. Deze ondernemers lopen daardoor meer risico's als het gaat om duurzame inzetbaarheid dan werknemers.

Een aantal andere kenmerken liet bij de vergelijking van zelfstandig ondernemers zonder personeel en werknemers geen statistisch significante verschillen, een effectgrootte van minder dan 0,20 of na correctie een effectgrootte van minder dan 0,20 zien. Omdat de kans dat kleinere verschillen worden veroorzaakt door methodologische verschillen tussen de NEA en de ZEA (de volgorde van de vragen 
kan bijvoorbeeld al van invloed zijn), hebben we deze niet beschreven. Dit betrof het verzuimpercentage, de ervaren gezondheid, de werktevredenheid, de aansluiting tussen kennis en vaardigheden, de moeilijkheidsgraad/cognitieve belasting en de tevredenheid met de arbeidsomstandigheden.

In een multivariate analyse, waarbij wordt gecorrigeerd voor geslacht, leeftijd, onderwijsniveau en bedrijfstak, blijven alle hierboven gepresenteerde verschillen statistisch significant. Ook blijft de effectgrootte bij al deze variabelen minimaal 0,20 (Cohen's d). Wel worden veel van de verschillen na correctie (iets) kleiner, een aantal bleef gelijk en één verschil werd iets groter (zie tabel 4).

Tabel $4 \quad$ Verschillen in duurzame inzetbaarheid zelfstandig ondernemers zonder personeel en werknemers: univariaat en multivariaat (na correctie voor geslacht, leeftijd, onderwijsniveau en bedrijfstak)

\begin{tabular}{lcc}
\hline & \multicolumn{2}{c}{$\begin{array}{c}\text { Zelfstandig ondernemers } \\
\text { zonder personeel ten opzichte } \\
\text { van werknemers }\end{array}$} \\
& $\begin{array}{c}\beta_{\text {Univariaat }} \\
\beta_{\text {Multivariaat }}\end{array}$ \\
\hline Goed functioneren & $+0,08$ & $+0,08$ \\
Door willen werken tot $\ldots$ jaar & $+0,13$ & $+0,09$ \\
Door kunnen werken tot $\ldots$ jaar & $+0,15$ & $+0,10$ \\
Burn-outklachten & $-0,06$ & $-0,06$ \\
Behoefte aan opleiding & $+0,08$ & $+0,06$ \\
Bevlogenheid & $+0,09$ & $+0,07$ \\
Privé-werkconflict & $+0,08$ & $+0,07$ \\
Werkdruk/taakeisen & $-0,07$ & $-0,08$ \\
Autonomie & $+0,19$ & $+0,14$ \\
Gevarieerd werk & $+0,10$ & $+0,08$ \\
Zwaar werk & $+0,09$ & $+0,08$ \\
Fysieke belasting & $-0,09$ & $-0,09$ \\
\hline
\end{tabular}

Alle verschillen zijn significant $(p<0,00 \mathrm{I})$ \& Cohen's $d \geq 0,20$. $\beta$ : gestandaardiseerde regressiecoëfficiënt.

\section{Noot}

1 De gewogen bruto respons is gedefinieerd als het totaal aantal ontvangen vragenlijsten gedeeld door de uitgezette steekproef, gecorrigeerd voor over- en ondervertegenwoordiging van bepaalde groepen in de steekproef. Een deel van de ontvangen vragenlijsten bleek niet bruikbaar door kaderfouten en doordat ze dubbel of onvolledig waren ingevuld. Het aantal bruikbare responsen bedroeg 37.973 voor de NEA en 4.796 voor de ZEA, waarvan 3.745 zelfstandig ondernemers zonder personeel. De NEA is uitgevoerd via internet en papier en de ZEA uitsluitend via internet. 


\section{Literatuur}

Brouwer, S., Lange, A. de, Mei, S. van der, Wessels, M., Koolhaas, W., Bültmann, U., Heijden, B. van der \& Klink, J. van der (2012). Duurzame inzetbaarheid van de oudere werknemer: stand van zaken. Groningen: Universitair Medisch Centrum, Rijksuniversiteit Groningen.

Cohen, J. (1988). Statistical power analysis for the behavioral sciences (2nd edition). New York: Taylor \& Francis.

Hooftman, W.E., Mars, G.M.J., Janssen, B., Vroome, E.M.M. de \& Bossche, S.N.J. van den (2015). Nationale Enquête Arbeidsomstandigheden 2014: Methodologie en globale resultaten. Leiden/Heerlen: TNO/CBS.

Janssen, B.J.M., Torre, W. van der, Vroome, E.M.M. de, Mol, M., Janssen, B. \& Bossche, S.N.J. van den (2015). Zelfstandigen Enquête Arbeid 2015: Methodologie en beschrijvende resultaten. Heerlen/Leiden: CBS/TNO.

Kösters, L. (2016). CBS-berichten: Nieuwe data over demografie, soort werk en inkomsten van zzp'ers. Tijdschrift voor Arbeidsvraagstukken, 32(1), 66-74.

Kraan, K.O., Zwieten, M.H.J. van, Sanders, J.M.A.F. \& Wevers, C.W.J. (2014). Monitor Duurzame Inzetbaarheid - Resultaten 2010 en 2012 en Methodologie. Leiden: TNO.

Ministerie van Financiën (2015). IBO Zelfstandigen zonder personeel. Den Haag: Ministerie van Financiën.

Torre, W. van der, Ven, H.A. van de, Dirven, H.J., Vroome, E.M.M. de, Schous, F.J., Preenen, P.T.Y., Daníelsson, P. \& Bossche S.N.J. van den (2016). Duurzame inzetbaarheid: zzp'ers versus werknemers. Een vergelijking tussen de duurzame inzetbaarheid van zelfstandig ondernemers en werknemers. Leiden: TNO.

Vlasblom, J. D., Echtelt, P. van \& Voogd-Hamelink, M. de (2015). Aanbod van arbeid 2014. Den Haag: Sociaal en Cultureel Planbureau. 